Research Article

\title{
Study on Stress Distribution Law of High-Efficiency Paste Backfilling Working Face with Solid Waste in Thick Coal Seam
}

\author{
Meng Zhang $\mathbb{D}^{1}$ and Dan Fang $\mathbb{D}^{2}$ \\ ${ }^{1}$ School of Civil \& Architecture Engineering, Xi'an Technological University, Xi'an 710021, China \\ ${ }^{2}$ School of Art and Media, Xi'an Technological University, Xi'an 710021, China \\ Correspondence should be addressed to Dan Fang; fangdan992@gmail.com
}

Received 13 November 2020; Revised 7 December 2020; Accepted 10 December 2020; Published 22 December 2020

Academic Editor: Erol Yilmaz

Copyright (C) 2020 Meng Zhang and Dan Fang. This is an open access article distributed under the Creative Commons Attribution License, which permits unrestricted use, distribution, and reproduction in any medium, provided the original work is properly cited.

\begin{abstract}
The high-efficiency paste backfilling mining technology of solid waste in thick coal seam above $6 \mathrm{~m}$ is a complex system engineering, which involves mining, backfilling, supporting, subsidence, safety, and other aspects, so it is of great strategic significance to study the technology. In this paper, on the basis of comprehensive research methods such as laboratory experiments, theoretical analysis, computer programming, and other comprehensive research methods, aiming at the problems of low production capacity and high paste backfilling cost, taking the mining of No. 3 Coal Seam under buildings in Lu'an area as the research object, the stress distribution law of high-efficiency paste backfilling working face with solid waste in more than 6-meter-thick coal seam was carried out. The main achievements are as follows: On the basis of the theoretical establishment of the program method for the instability discriminant analysis of roof rock beam failure with the change of backfilling body unit strength with time, a numerical calculation model considering the change process of backfilling body strength is established. The stress distribution analysis of the E1302 working face before and during the mining process plays a guiding role in the actual production of the whole working face and roadway. The research results support the sustainable development of coal mining enterprises from technology, which has great economic, social, and environmental benefits, and can promote the industrialization of green mining high-tech in Shanxi Province and even the whole country and can promote the green mining technology progress of paste backfilling in coal mines in China, which is of great significance to the sustainable development of mining production and environmental construction.
\end{abstract}

\section{Introduction}

BP world energy statistical yearbook (2018) [1] points out that, in 2017, the proportion of coal in China's energy structure dropped from $73.6 \%$ a decade ago and $62.0 \%$ in 2016 to $60.4 \%$ in 2017 . However, coal is still the main energy source. However, for a long time, China's coal resource mining has ignored the cost of resources and the environment, resulting in a low recovery rate of coal resources, high waste emissions, and serious environmental damage [2-4]. The key to the sustainable development of coal mining is to solve the contradiction between coal mining and environmental protection in the world [5-13]. Solid waste paste backfilling mining is an important part of green coal mining advocated by Academician Qian et al. [14-19], which can effectively solve the serious waste of resources, low recovery rate, and ecological and environmental damage caused by high-intensity mining $[20,21]$.

By the end of 2014, Gaohe coal mine had 271 million tons of coal reserves under buildings. The cost of roadway excavation, waste discharge, mine water treatment, and resource tax can be saved by backfilling mining technology, which is about 50 yuan/T. If the increased cost of backfilling is 80 yuan/ $\mathrm{T}$, the comprehensive increase of coal cost per ton is only 30 yuan/T. The backfilling output only accounts for $18 \%$ of the total output of the mine, resulting in an increase of only 5.4 yuan/ $\mathrm{T}$ in the cost per ton of coal, but it will extend the service life of the mine by more than 25 years.

At present, some coal mines in China have carried out the industrial practice of high mining height and highefficiency paste backfilling by canceling isolation class and solidification class, but the numerical simulation research on 
the stress distribution law of paste backfilling face has not kept pace with the pace of production practice. For the highefficiency paste filling of solid waste, it is necessary to study the rock control technology under the condition of two classes and one cycle of "mining filling" and even backfilling while mining, that is, to study the stress distribution law of high-efficiency paste backfilling working face in more than $6 \mathrm{~m}$ thick coal seam, so as to meet the needs of backfilling mining in high-yield and high-efficiency mines.

\section{Project Overview}

2.1. Model Building. In this paper, FLAC3D software [22, 23] is used to establish a three-dimensional numerical simulation model based on the geological conditions of Gaohe mine and the E1302 backfilling working face. The upper boundary of the model is the position of the main key layer calculated by theory, and the lower boundary is $50 \mathrm{~m}$ below the coal seam floor. The upper and lower height is $175 \mathrm{~m}$, and the length and width of the model are $700 \mathrm{~m} * 500 \mathrm{~m}$. Considering that abnormal pressure may occur in the working face when the working face advances to half of its length, $230 \mathrm{~m}$ of goaf is reserved in the south of E1302 backfilling working face, the coal pillar between the goaf and the cut hole in E1302 working face is $50 \mathrm{~m}$, the advancing length of the working face is $390 \mathrm{~m}$, and the distance between the stopping line and the boundary is $80 \mathrm{~m}$. Considering the boundary effect and the influence of goaf, the E1302 ventilation roadway is $100 \mathrm{~m}$ away from the boundary, and the coal pillar between the E1302 ventilation roadway and E1302 intake roadway is $20 \mathrm{~m}$. The length of the E1302 backfilling working face is $230 \mathrm{~m}$, and the distance between the E1302 auxiliary transport roadway and E1302 transport roadway is $30 \mathrm{~m}$, as shown in Figure 1.

2.2. Mechanical Parameters of Coal (Rock). The physical properties of surrounding rock in the model refer to the histogram of the roof and floor strata and the test report of coal (rock) mechanical properties of E1302 working face in Gaohe coal mine [2], and some mechanical parameters of coal (rock) are shown in Table 1.

Because the measured rock mechanical parameters are measured in a two-dimensional state, and the rock mass is in a three-dimensional state in the actual simulation, the mechanical parameters in the simulation need to be modified by inversion of the measured data and finally used as the simulation parameters.

2.3. Boundary Conditions and Constitutive Model. The displacement boundary conditions are selected for the front, back, left, right, and bottom of the model, and the stress boundary conditions are selected for the top of the model. The horizontal displacements of the left and right and the front and back boundaries are fixed, and the horizontal and vertical displacements of the lower boundary are fixed. In the upper part of the model, the dead weight of overlying strata is applied according to the uniform load. In this simulation, the buried depth of the coal body is $400 \mathrm{~m}$, the stress boundary conditions are applied to the upper boundary of the unit body, and the original rock stress is applied to the model. In this simulation, the Moore Coulomb plastic model is adopted, and the initial equilibrium of the model is shown in Figure 2.

2.4. Simulation Steps. The actual construction process of the mine is as follows: first excavate E1302 ventilation roadway, E1302 intake roadway, and E1302 auxiliary transport roadway to serve the extraction of E1302 working face (i.e., the gob part of E1302 working face); after it is stable, excavate E1302 transport roadway (roadway name in the current figure) to serve E1303 working face (the current E1303 working face goaf); after it is stable, the cut hole is excavated to serve E1302 backfilling working face; the interval between backfilling and mining is a cycle mode of two mining and one backfilling; the simulation steps are carried out according to the actual construction steps.

\section{Numerical Simulation Optimization}

3.1. Stress Distribution before Mining in E1302 Paste Backfilling Working Face. Because E1302 backfilling working has been affected by the mining during the previous working face before mining, and the goaf on both sides of the working face is asymmetric, which leads to the different-stress environment in different positions of the roadway before mining. Therefore, it is necessary to analyze and study the stress in different positions of the roadway. This section analyzes and studies the vertical stress of the cut hole, E1302 auxiliary transport roadway, and E1302 intake roadway before mining, and the research results are used to guide the production practice of working face.

3.1.1. Stress Distribution of Cut Hole before Mining in E1302 Paste Backfilling Working Face. Due to the different-stress environment on both sides of the E1302 backfilling and mining working face, the vertical stress distribution of different positions of the cut hole is shown in Figure 3.

The following can be seen from Figure 4:

(1) In the vicinity of the cut hole, the maximum vertical stress in the vertical direction of the auxiliary roadway side is mainly concentrated near the coal pillar side. With the increase of the distance from the cut hole, the maximum vertical stress gradually transfers to the working face side of the roadway, and the vertical stress of the coal body at the working face side is generally greater than that of the coal pillar side (excluding the plastic zone near the cut hole)

(2) It can be seen from the cross section of the auxiliary haulage roadway within the scope of $0 \mathrm{~m} \sim 20 \mathrm{~m}$ that the stress concentration coefficient of the coal body in the working face side of the roadway increases first and then decreases; the maximum stress concentration coefficient near the side of the roadway $5 \mathrm{~m}$ away from the cut hole can reach about 2.51, the maximum stress concentration 


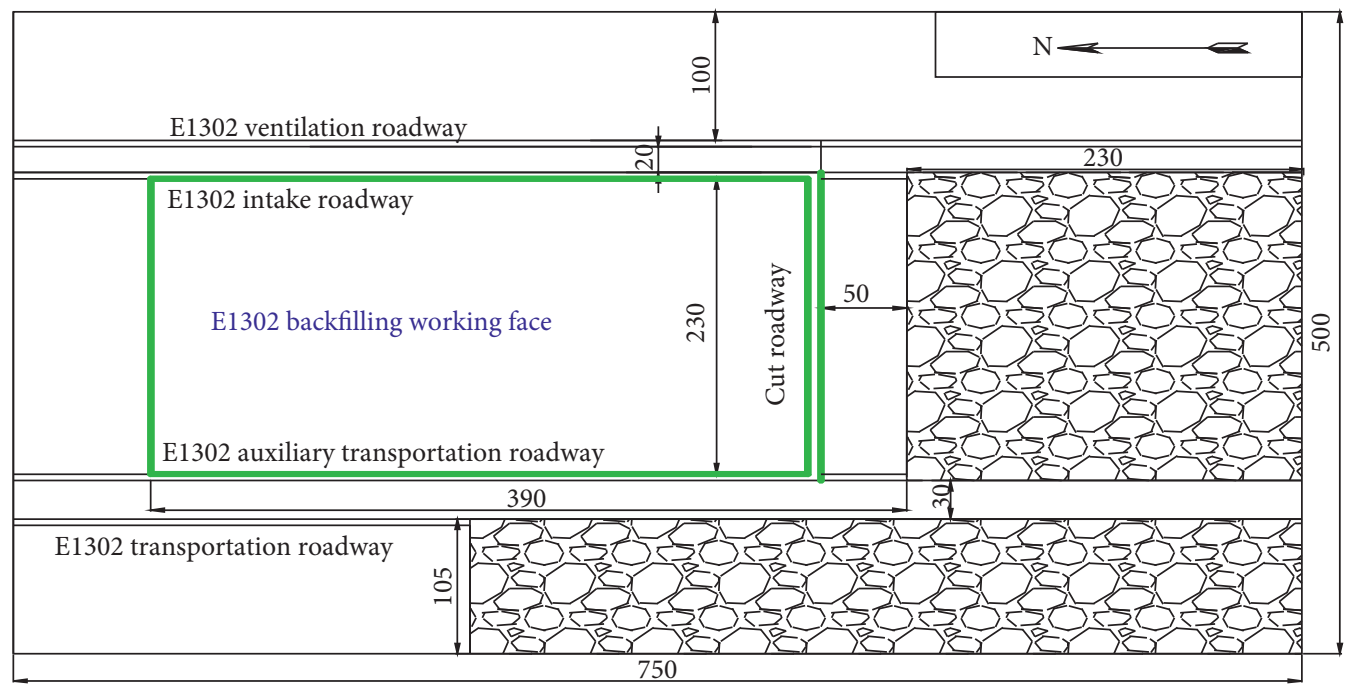

FIgURE 1: E1302 working face mining plane schematic.

Table 1: Coal (rock) mechanical parameters.

\begin{tabular}{|c|c|c|c|c|c|c|}
\hline \multirow[b]{2}{*}{ Layer } & & \multicolumn{5}{|c|}{ Parameters } \\
\hline & & $\begin{array}{c}\text { Tensile strength } \\
(\mathrm{MPa})\end{array}$ & $\begin{array}{l}\text { Elastic modulus } \\
(\mathrm{GPa})\end{array}$ & $\begin{array}{l}\text { Poisson's } \\
\text { ratio }\end{array}$ & $\begin{array}{c}\text { Cohesion } \\
(\mathrm{MPa})\end{array}$ & $\begin{array}{l}\text { Internal friction } \\
\text { angle }\left({ }^{\circ}\right)\end{array}$ \\
\hline Upper strata & $\begin{array}{l}\text { Medium grained } \\
\text { sandstone }\end{array}$ & 4.32 & 32.12 & 0.23 & 2.72 & 25 \\
\hline Main roof & Siltstone & 3.56 & 21.16 & 0.23 & 2.02 & 26 \\
\hline Direct roof & Sandy mudstone & 2.18 & 15.73 & 0.25 & 1.19 & 31 \\
\hline Coal seam & Coal & 1.35 & 1.73 & 0.29 & 0.53 & 29 \\
\hline $\begin{array}{l}\text { Immediate } \\
\text { floor }\end{array}$ & Sandy mudstone & 1.65 & 13.73 & 0.24 & 1.09 & 30 \\
\hline
\end{tabular}

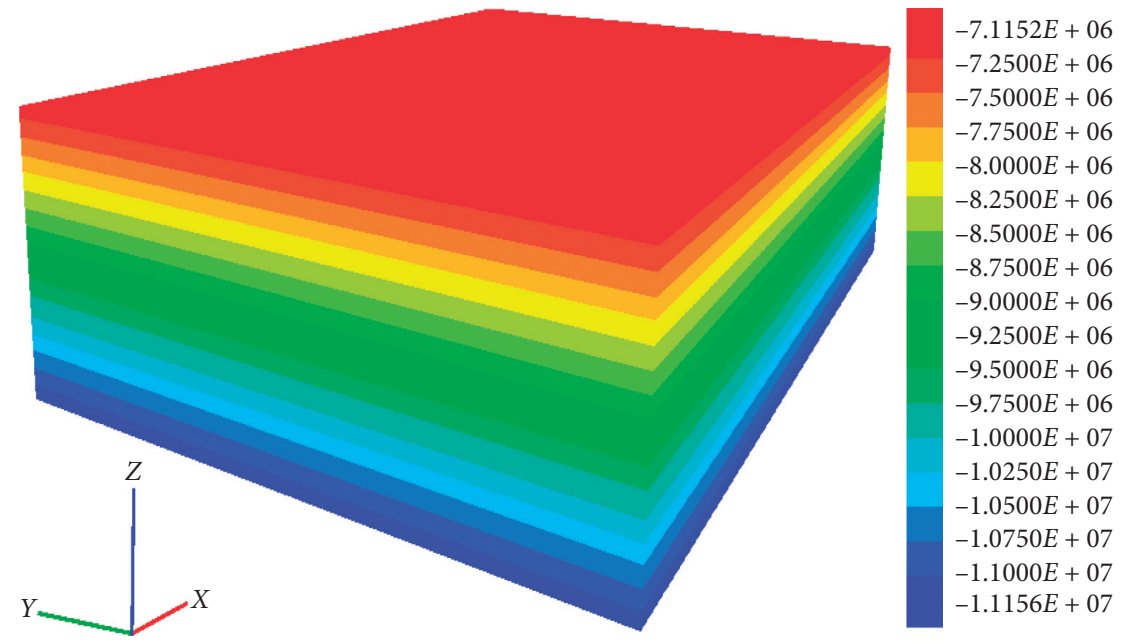

FIgURE 2: Model initial balance diagram.

coefficient near the roadway side $10 \mathrm{~m}$ away from the cut hole can reach about 2.53 , and the maximum stress concentration coefficient near the roadway side $15 \mathrm{~m}$ away from the cut hole can reach about 2.4. It can be seen that the part affected by E1303 and E1302 working face goaf is mainly concentrated in the range of 20 me ahead of the roadway, and the maximum value of stress concentration coefficient near the roadway side will appear between $5 \mathrm{~m}$ and $15 \mathrm{~m}$ away from the cut hole 


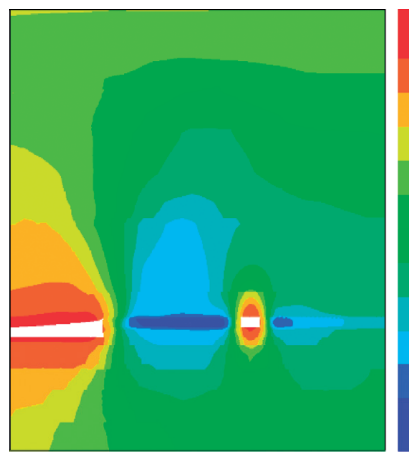

(a)

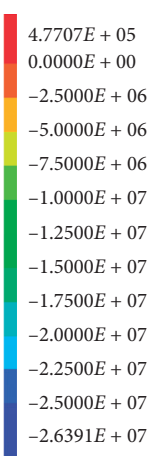

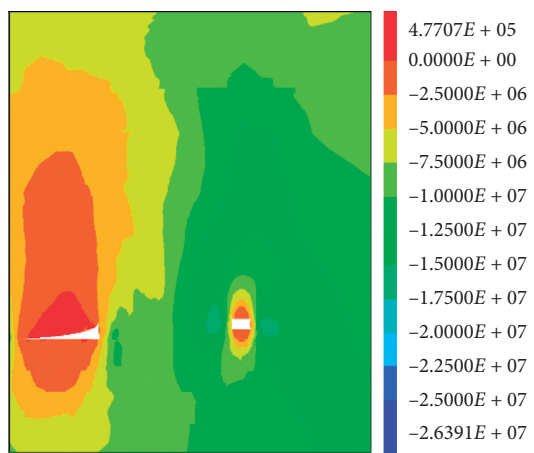

(b)

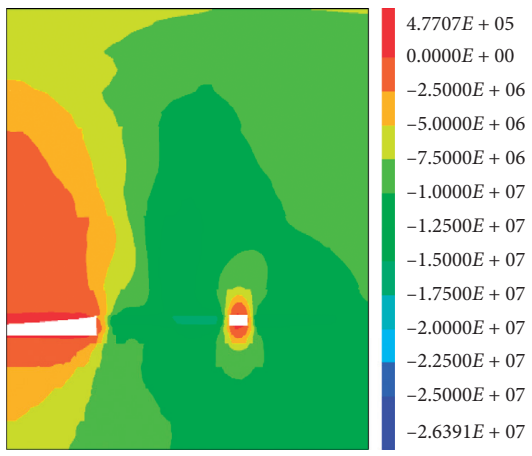

(c)

FIgURE 3: Vertical stress nephogram of cut hole.

(3) Mainly affected by the goaf of E1303 working face, the stress distribution of auxiliary transportation roadway is shown in Figure 5

In Figure 3, the roadway on the right side is the cut hole, and the left side is the E1302 goaf; Figure 3(a) refers to the section of the cut hole at $5 \mathrm{~m}$ away from the E1302 auxiliary transport roadway; Figure 3(b) refers to the section of the cut hole at $115 \mathrm{~m}$ away from the E1302 auxiliary transport roadway (the middle of the cut hole); Figure 3(c) refers to the section of the cut hole at $5 \mathrm{~m}$ away from the E1302 intake roadway.

The following can be seen from Figure 3:

(1) In the part near the goaf side of the E1303 working face, under the roof pressure of overlying strata on the goaf side of the E1303 working face and E1302 working face, the deformation of the cut hole is large. The maximum stress concentration factor is about 2.6, which mainly concentrates on the coal pillar between E1302 backfilling working face and goaf, as well as the upper strata of goaf

(2) With the distance from the goaf farther and farther, the influence of the goaf of E1303 working face goaf is less and less, and it is mainly affected by the goaf of E1302 working face

3.1.2. Stress Distribution of the Auxiliary Transport Roadway before Mining in E1302 Paste Backfilling Working Face. As the eastern section of E1302 auxiliary transport roadway is the goaf of E1303 working face and the south of E1302 working face, considering that it will be affected by the goaf, the E1302 auxiliary transportation roadway is divided into three parts: (1) the part affected by the goaf of E1303 working face and E1302 working face, (2) the part mainly affected by the goaf of E1303 working face, and (3) the part less affected by the goaf of E1303 working face. This section mainly analyzes the first two parts.

(1) Under the comprehensive influence of E1302 and E1303 working face goaf, the stress distribution of auxiliary transportation roadway is shown in Figure 4; the eight pictures in Figure 4 are the profile stress nephogram in the vertical direction of roadway every $5 \mathrm{~m}$ within the scope of $0 \mathrm{~m} \sim 35 \mathrm{~m}$ from the cut hole, the right roadway in Figure 4 is E1302 auxiliary transport roadway, and the left is E1303 working face goaf

Figure 5 shows the profile stress nephogram in the vertical direction of the auxiliary haulage roadway at intervals of $10 \mathrm{~m}$ from $160 \mathrm{~m}$ to $240 \mathrm{~m}$ from the cut hole. Among them, before $200 \mathrm{~m}$, the left side of E1302 auxiliary transportation is the goaf of E1303 working face; after $200 \mathrm{~m}$, the left side of E1302 auxiliary transport roadway is E1302 transport roadway, and $200 \mathrm{~m}$ is the end of E1303 working face goaf.

The following can be seen from Figure 5:

(1) In the range of $160 \mathrm{~m} \sim 200 \mathrm{~m}$ away from the cut hole, the vertical stress in the coal body side of the transport roadway working face is relatively concentrated compared with the coal pillar side 


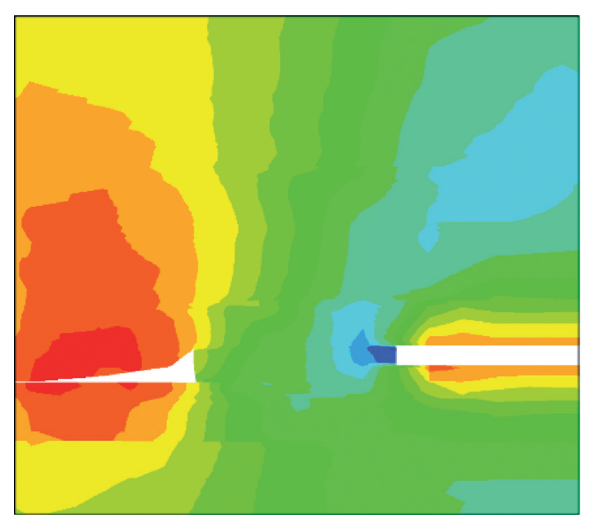

(a)

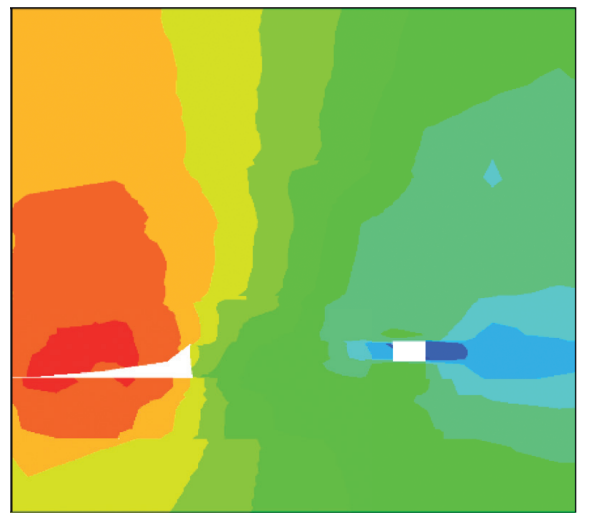

(c)

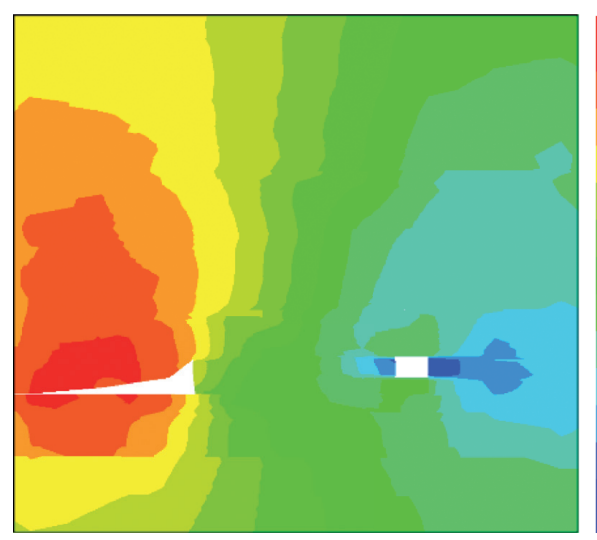

(e)

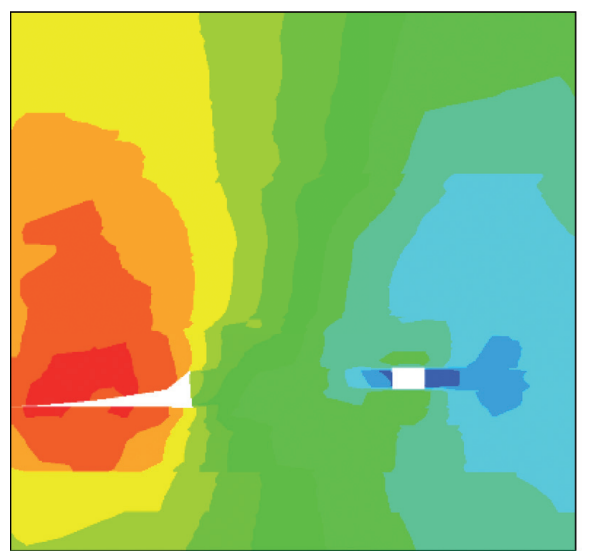

(g)
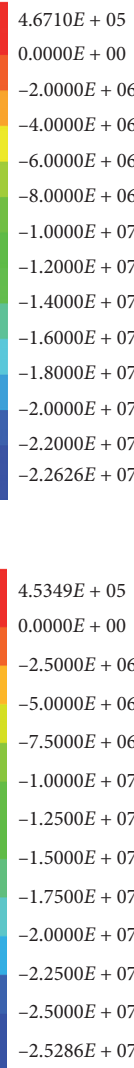

$4.2710 E+05$ $0.0000 E+00$

$-2.0000 E+06$

$-4.0000 E+06$

$-6.0000 E+06$

$-8.0000 E+06$

$-1.0000 E+07$

$-1.2000 E+07$

$-1.4000 E+07$

$-1.6000 E+07$

$-1.8000 E+07$

$-2.0000 E+07$

$-2.2000 E+07$

$-2.3299 E+07$

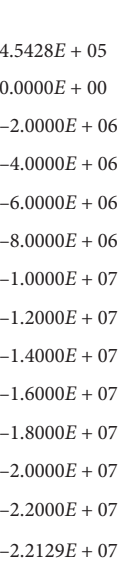

$-2.2129 E+07$

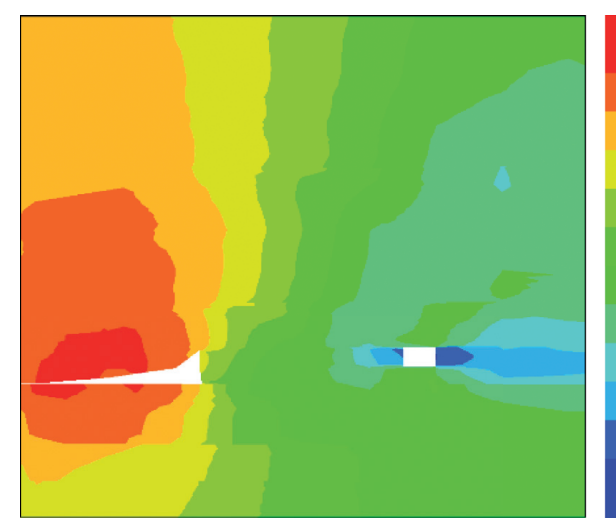

$4.8182 E+05$ $0.0000 E+00$

$-2.5000 E+06$ $-5.0000 E+06$ $-7.5000 E+06$ $-1.0000 E+07$ $-1.2500 E+07$ $-1.5000 E+07$ $-1.7500 E+07$ $-2.0000 E+07$ $-2.2500 E+07$ $-2.5000 E+07$ $-2.5112 E+07$

(b)



$4.1087 E+05$ $0.0000 E+00$

$-2.0000 E+06$ $-4.0000 E+06$ $-6.0000 E+06$ $-8.0000 E+06$ $-1.0000 E+07$ $-1.2000 E+07$ $-1.4000 E+07$ $-1.6000 E+07$ $-1.8000 E+07$ $-2.0000 E+07$ $-2.2000 E+07$ $-2.4000 E+07$ $-2.4159 E+07$

(d)

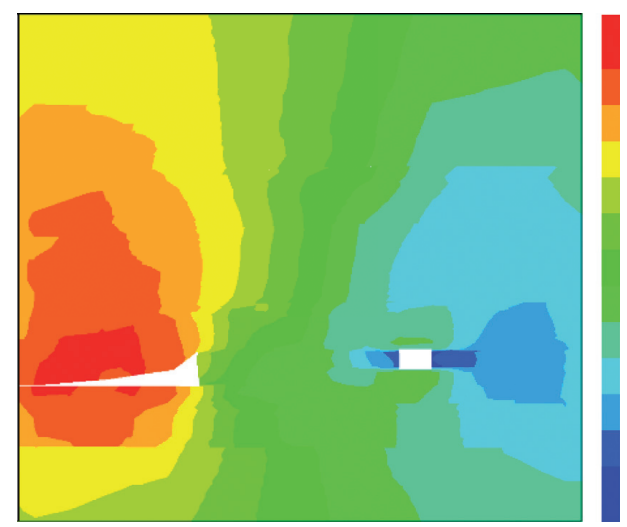

$4.2357 E+05$

$0.0000 E+00$

$-2.0000 E+06$

$-4.0000 E+06$

$-6.0000 E+06$

$-8.0000 E+06$

$-1.0000 E+07$

$-1.2000 E+07$

$-1.4000 E+07$

$-1.6000 E+07$

$-1.8000 E+07$

$-2.0000 E+07$

$-2.2000 E+07$

$-2.2646 E+07$

(f)



$4.4035 E+05$

$0.0000 E+00$

$-2.0000 E+06$

$-4.0000 E+06$

$-6.0000 E+06$

$-8.0000 E+06$

$-1.0000 E+07$

$-1.2000 E+07$

$-1.4000 E+07$

$-1.6000 E+07$

$-1.8000 E+07$

$-2.0000 E+07$

$-2.1695 E+07$

(h)

Figure 4: Vertical stress nephogram of auxiliary transport roadway: (a) $0 \mathrm{~m}$, (b) $5 \mathrm{~m}$, (c) $10 \mathrm{~m}$, (d) $15 \mathrm{~m}$, (e) $20 \mathrm{~m}$, (f) $25 \mathrm{~m}$, (g) $30 \mathrm{~m}$, and (h) $35 \mathrm{~m}$. 


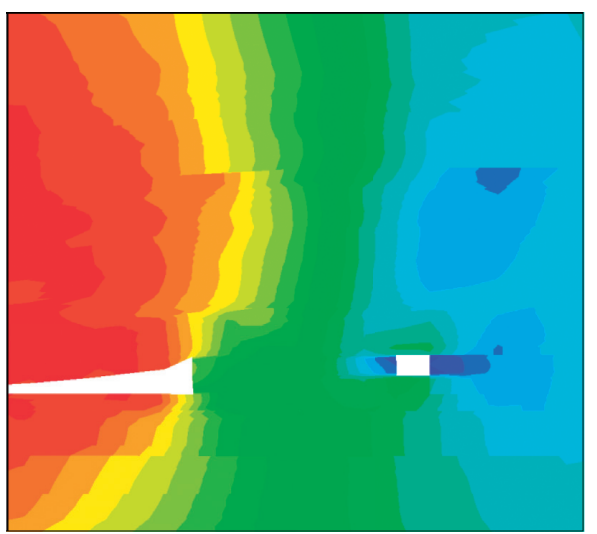

(a)

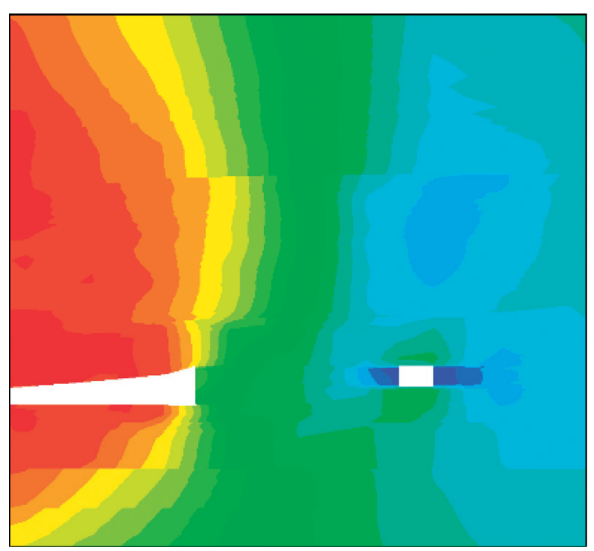

(c)

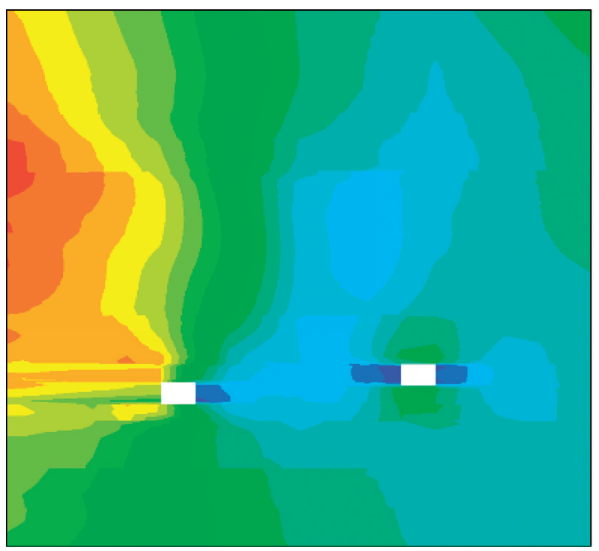

(e)

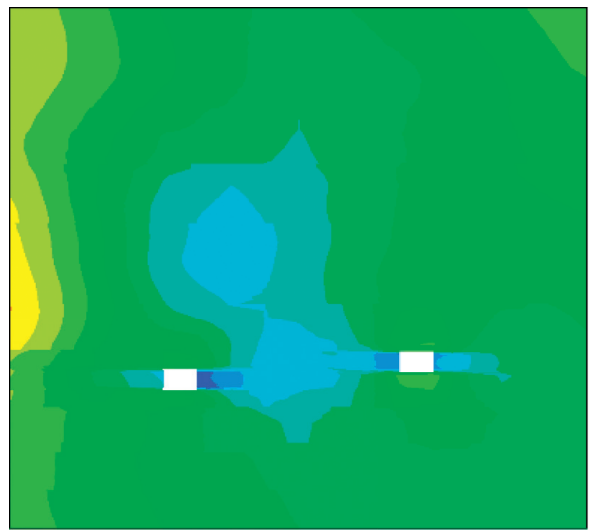

(g)



$4.4682 E+05$

.0000E + 00

$1.0000 E+06$

$-3.0000 E+06$

$-4.0000 E+06$

$-5.0000 E+06$

$-6.0000 E+06$

$-7.0000 E+06$

$-8.0000 E+06$

$-9.0000 E+06$

$-1.0000 E+07$

$-1.1000 E+07$

$-1.2000 E+07$

$-1.3000 E+07$

$-1.4000 E+07$

$-1.5000 E+07$

$-1.6000 E+07$

$-1.7000 E+07$

$-1.7000 E+07$

(b)

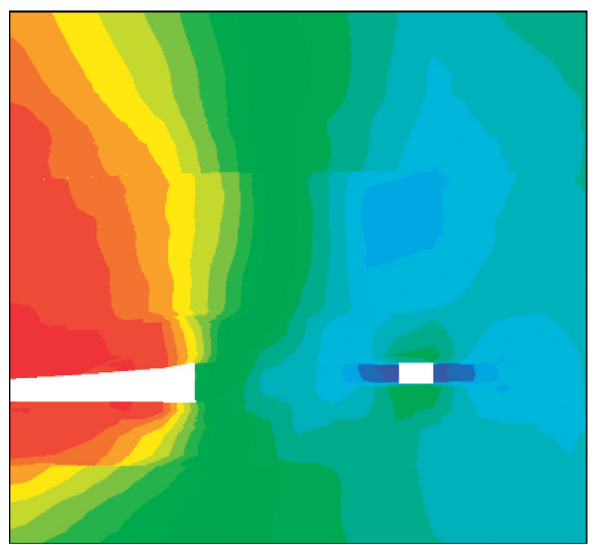

$3.3358 E+05$ $0.0000 E+00$

$-1.0000 E+06$

$-2.0000 E+06$

$-3.0000 E+06$

$-4.0000 E+06$

$-5.0000 E+06$

$-6.0000 E+06$

$-7.0000 E+06$

$-8.0000 E+06$

$-9.0000 E+06$

$-1.0000 E+07$

$-1.1000 E+07$

$-1.2000 E+07$

$-1.3000 E+07$

$1.4000 E+07$

$-1.5000 E+07$

$-1.6000 E+07$

$-1.7000 E+07$

$-1.7464 E+07$

(d)



$-2.4777 E+06$ $-3.0000 E+06$

$-4.0000 E+06$

$-5.0000 E+06$

$-6.0000 E+06$

$-7.0000 E+06$

$-8.0000 E+06$

$-9.0000 E+06$

$-1.0000 E+07$

$-1.1000 E+07$

$-1.2000 E+07$

$-1.3000 E+07$

$-1.4000 E+07$

$-1.5000 E+07$

$-1.6000 E+07$

$-1.7000 E+07$

$-1.7386 E+07$

(f)

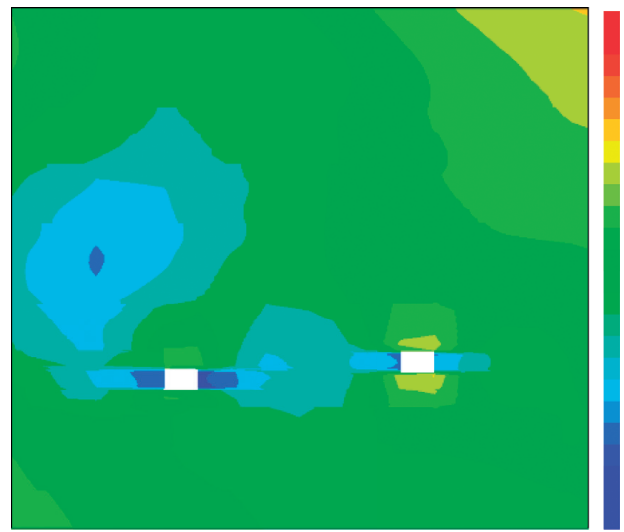

$-6.3392 E+06$

$-7.0000 E+06$

$-8.0000 E+06$

$-9.0000 E+06$

$-1.0000 E+07$

$-1.1000 E+07$

$-1.2000 E+07$

$-1.3000 E+07$

$-1.4000 E+07$

$-1.5000 E+07$

$-1.6000 E+07$

$-1.6263 E+07$

(h)

Figure 5: Vertical stress nephogram of auxiliary transport roadway: (a) $160 \mathrm{~m}$. (b) $170 \mathrm{~m}$, (c) $180 \mathrm{~m}$, (d) $190 \mathrm{~m}$, (e) $200 \mathrm{~m}$, (f) $210 \mathrm{~m}$, (g) $220 \mathrm{~m}$, and (h) $230 \mathrm{~m}$. 
(2) When the distance from the cut hole is more than $200 \mathrm{~m}$, affected by the goaf of E1303 working face, the stress in both sides of the E1302 transport roadway is relatively concentrated. With the distance from the cut hole getting farther and farther, the stress on both sides of the roadway gradually decreases and finally tends to be stable

3.2. Stress Distribution in the Mining Process of E1302 Paste Backfilling Working Face. The previous section mainly analyzes the stress distribution of the E1302 backfilling working face before mining; this section analyzes the stress distribution of working face and overburdens rock during the mining process of the E1302 backfilling working face. This paper mainly analyzes the stress distribution of overburden rock before cutting the first cutting coal, before cutting the second cutting coal, before backfilling and after backfilling, and before cutting the next cutting coal in four stages $(0 \mathrm{~m}$ from the cut hole, $100 \mathrm{~m}$ from the cut hole, $300 \mathrm{~m}$ from the cut hole, and after the completion of backfilling and mining).

\subsubsection{Stress Distribution of E1302 Working Face in Initial} Mining and Backfilling Stage. The initial mining stage of E1302 backfilling working face refers to the fact that after the completion of the excavation, the support equipment should be installed and the working face is about to be ready for mining; in this stage, the vertical stress distribution state of the working face in these four stages is analyzed before the working face advances the first knife, before the working face advances the second knife, before backfilling, and before the next coal cutting after backfilling, as shown in Figure 6 (Figure 6(a) refers to the top-down view, slicing along the roof of the working face, and Figure 6(b) refers to the cross section in the direction of I-I, which is made at $115 \mathrm{~m}$ away from E1302 auxiliary transport roadway. The meanings of (a) and (b) in Figures 7-9 are consistent with this).

The following can be seen from Figure 6:

(1) It can be seen from the top view (a) that the main factors affecting the E1302 backfilling working face are the coal pillar behind the working face and the coal pillar between the backfilling working face and E1303 working face. The stress concentration area mainly occurs in the coal pillar near the side of the E1302 auxiliary transport roadway between the goaf of the E1302 working face and the rear of the cut hole. The maximum stress concentration coefficient can reach 2.57 under the joint influence of the two goafs. In the four states of backfilling and mining cycle, the stress concentration in the process of coal mining has a slightly decreasing trend, and the stress concentration has a rising trend in a period of time after mining and in the backfilling process, which is mainly affected by the coal pillar in the initial mining stage

(2) It can be seen from the main view (b) in the figure that the stress in the middle of the working face is mainly concentrated in front of and behind the working face, and the stress concentration coefficient in the reserved coal pillar behind the working face is slightly greater than that in the front of the working face, which is mainly affected by the goaf of E1302 working face. In the four states in a cycle of backfilling and mining, the stress concentration changes little in the process of coal mining, and the stress tends to increase after mining and backfilling

(3) Comprehensive analysis shows that under the joint influence of E1302 and E1303 working faces and goaf, the stress of the coal pillar in this part is relatively concentrated, and the roadway left in this section needs to be strengthened support (it should be used when mining layered working face)

3.2.2. Stress Distribution of E1302 Backfilling Working Face $100 \mathrm{~m}$ away from the Cut Hole. In the initial mining stage, the working face is greatly affected by the goaf of E1302 working face in the south. This section mainly studies the stress distribution of the E1302 working face $100 \mathrm{~m}$ away from the cut hole. At this time, the E1302 working face is located in the middle of the E1302 cut hole and the E1303 working face's final mining position. A complete filling mining cycle is taken at 100 points away from the cutting hole. In this stage, the vertical stress distribution state of the working face in these four stages is analyzed before the working face advances the first knife, before the working face advances the second knife, before backfilling, and before the next coal cutting after backfilling, as shown in Figure 7.

The following can be seen from Figure 7:

(1) It can be seen from the top view (a) in the figure that the stress concentration area is still the coal pillar section affected by the goafs on both sides, and it will also be affected by mining. The stress concentration coefficient is about 2 within the range of about $50 \mathrm{~m}$ in front of the working face (close to the side of E1303 goaf). The direction stress from E1302 auxiliary transport roadway to E1302 intake roadway gradually decreases, and the stress of backfilling body behind the working face increases gradually from the cutting hole to the working face. In this stage, the vertical stress distribution changes little in a cycle, the stress concentration factor near the working face is about 2 , and the maximum stress concentration factor in the stress concentration area affected by multiple stresses can reach 3

(2) From the main view (b), it can be seen that the stress in the coal body in front of the middle of the working face is relatively concentrated, which increases first and then decreases gradually along the advancing direction of the working face. The maximum stress concentration coefficient can reach 1.92 within the range of 10 15 from the working face. The stress in the backfilling body behind the working face is smaller than that in the coal body in front of the working face, and the stress increases gradually from 

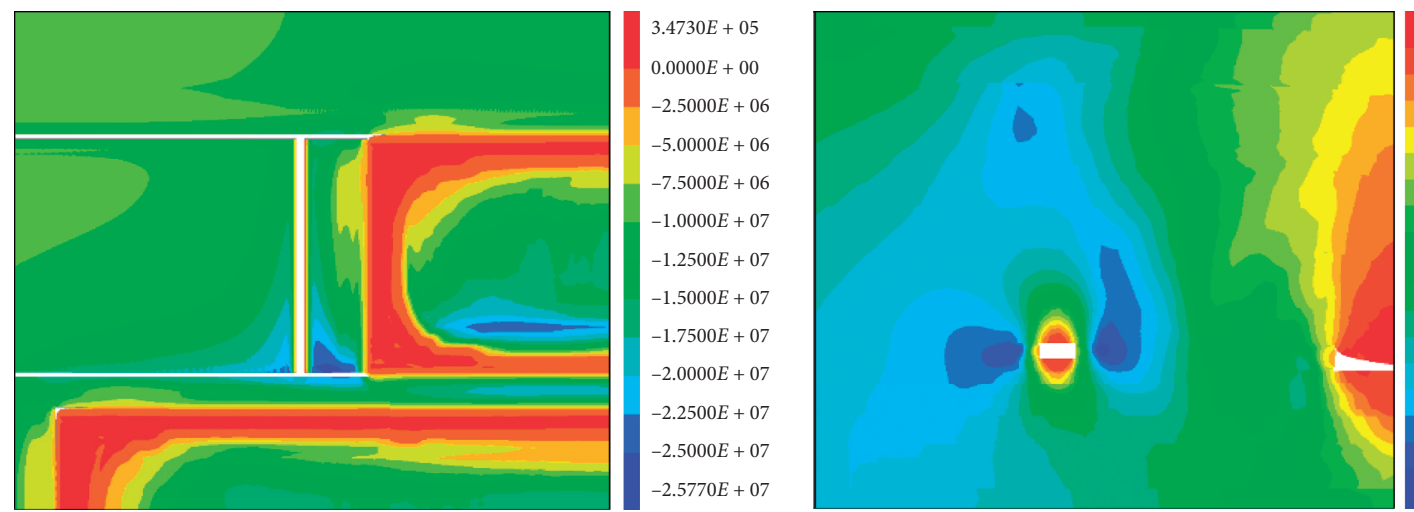

$2.4211 E+05$

$0.0000 E+00$

$-1.0000 E+06$

$-2.0000 E+06$

$-3.0000 E+06$

$-4.0000 E+06$

$-5.0000 E+06$

$-6.0000 E+06$

$-7.0000 E+06$

$-8.0000 E+06$

$-9.0000 E+06$

$-1.0000 E+07$

$-1.1000 E+07$

$-1.2000 E+07$

$-1.3000 E+07$

$-1.4000 E+07$

$-1.5000 E+07$

$-1.6000 E+07$

(a)



$3.5273 E+05$
$0.0000 E+00$
$-2.5000 E+06$
$-5.0000 E+06$
$-7.5000 E+06$
$-1.0000 E+07$
$-1.2500 E+07$
$-1.5000 E+07$
$-1.7500 E+07$
$-2.0000 E+07$
$-2.2500 E+07$
$-2.5000 E+07$
$-2.5448 E+07$

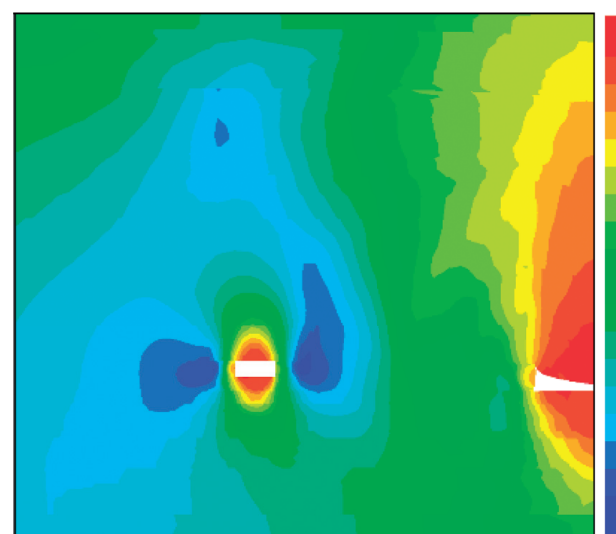

$2.4466 E+05$

$0.0000 E+00$

$-1.0000 E+06$

$-2.0000 E+06$

$-3.0000 E+06$

$-4.0000 E+06$

$-5.0000 E+06$

$-6.0000 E+06$

$-7.0000 E+06$

$-8.0000 E+06$

$-9.0000 E+06$

$-1.0000 E+07$

$-1.1000 E+07$

$-1.2000 E+07$

$-1.3000 E+07$

$-1.4000 E+07$

$-1.5000 E+07$

$-1.6000 E+07$

$-1.6895 E+07$

(b)


$2.3206 E+05$ $0.0000 E+00$

$-1.0000 E+06$

$-2.0000 E+06$

$-3.0000 E+06$

$-4.0000 E+06$

$-5.0000 E+06$

$-6.0000 E+06$

$-7.0000 E+06$

$-8.0000 E+06$

$-9.0000 E+06$

$-1.0000 E+07$

$-1.1000 E+07$

$-1.2000 E+07$

$-1.3000 E+07$

$-1.4000 E+07$

$-1.5000 E+07$

$-1.6000 E+07$

$-1.6989 E+07$

(c)
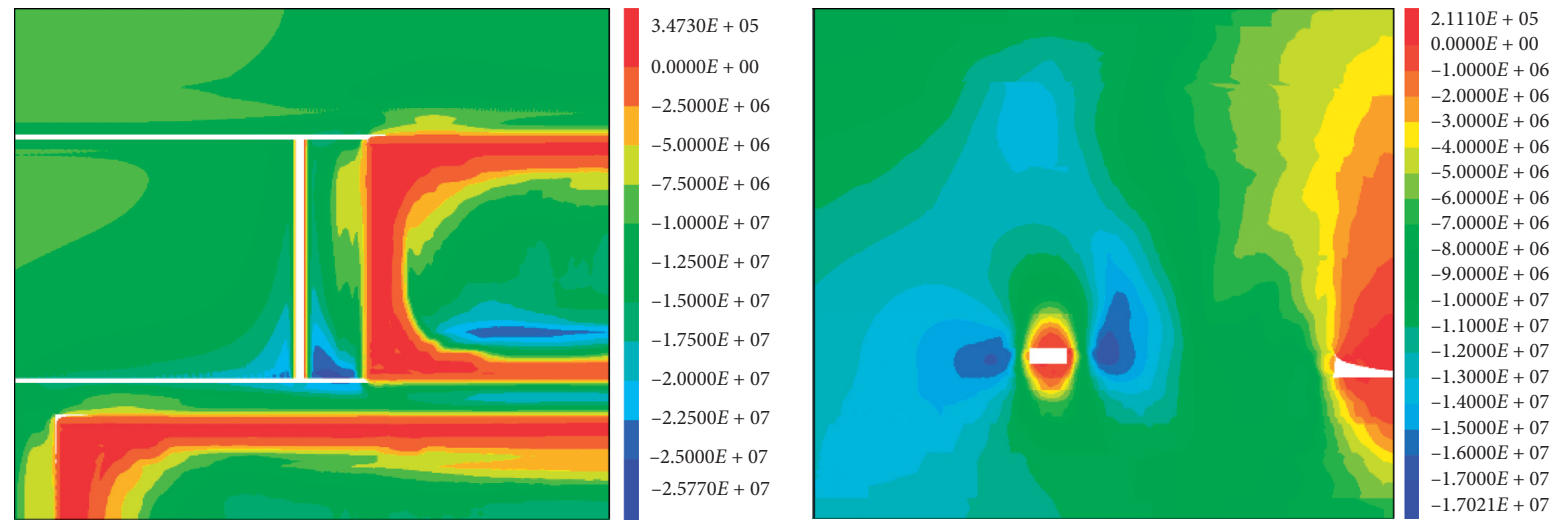

(d)

Figure 6: Nephogram of stress distribution in the initial mining stage of E1302 working face under a backfilling mining cycle. (a) Vertical stress distribution before cutting the first coal. (b) Vertical stress distribution before cutting the second coal. (c) Vertical stress distribution before backfilling. (d) Vertical stress distribution before the next coal cutting after backfilling. 



$-3.0050 E+07$

(a)
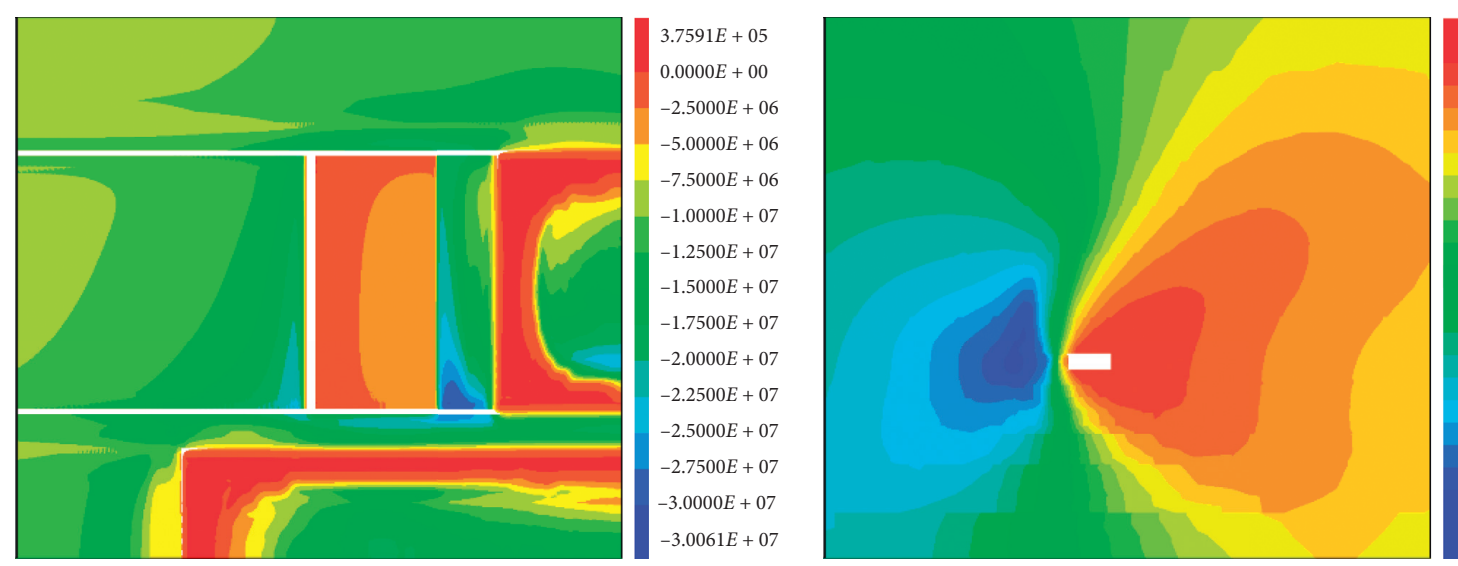

$2.2055 E+04$

$-1.0000 E+06$

$-3.0000 E+06$

$-5.0000 E+06$

$-7.0000 E+06$

$-9.0000 E+06$

$-1.1000 E+07$

$-1.3000 E+07$

$-1.5000 E+07$

$-1.7000 E+07$

$-1.9000 E+07$

$-1.9211 E+07$

(b)



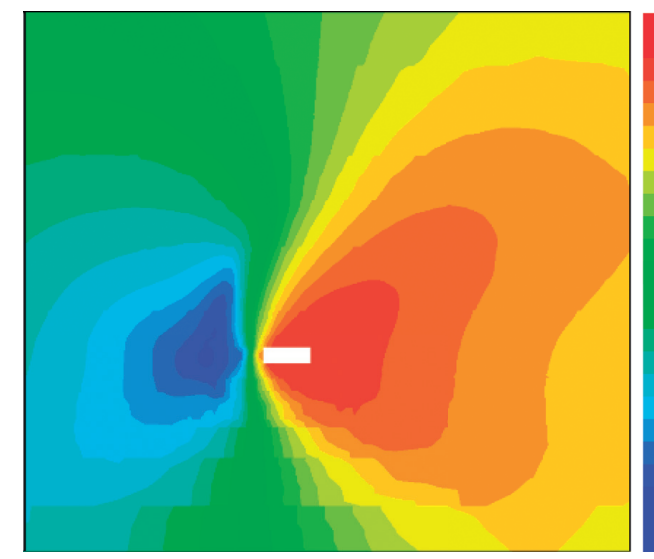

$3.1840 E+04$

$-1.0000 E+06$

$-3.0000 E+06$

$-5.0000 E+06$

$-7.0000 E+06$

$-9.0000 E+06$

$-1.1000 E+07$

$-1.3000 E+07$

$-1.5000 E+07$

$-1.7000 E+07$

$-1.9000 E+07$

$-1.9165 E+07$

(c)

Figure 7: Continued. 

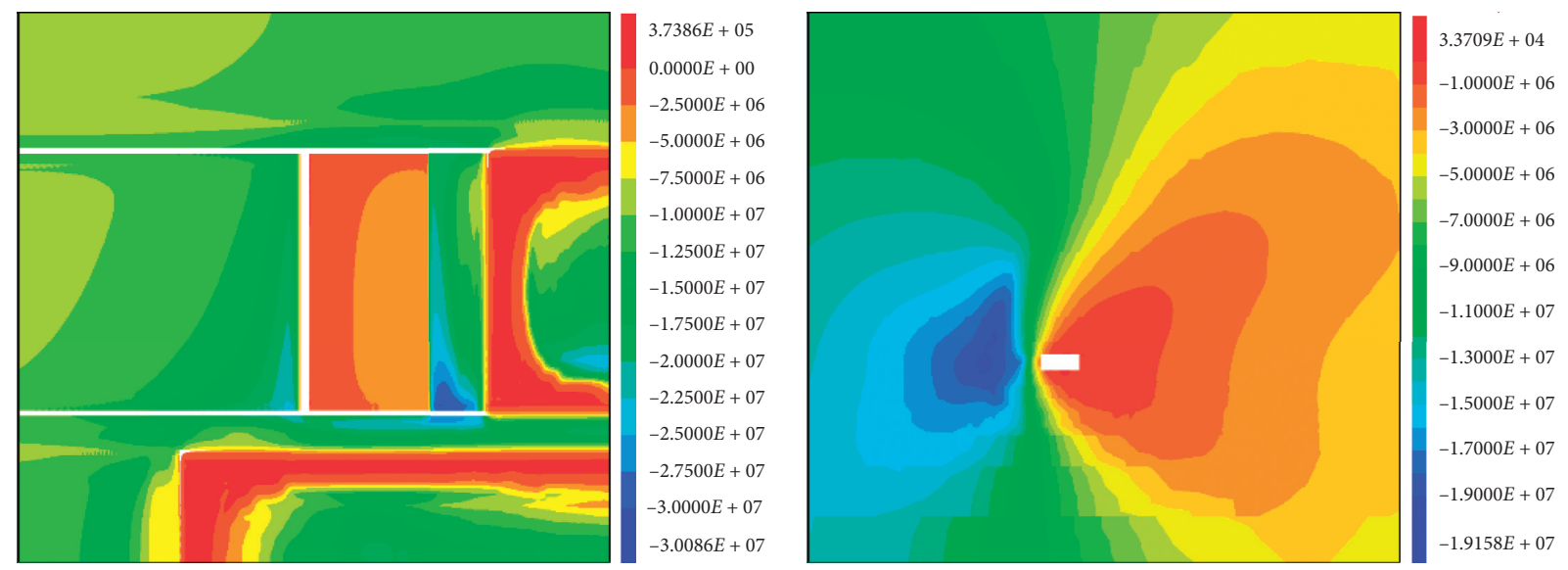

(d)

Figure 7: Nephogram of stress distribution $100 \mathrm{~m}$ away from the cut hole in E1302 working face under a backfilling mining cycle. (a) Vertical stress distribution before cutting the first coal. (b) Vertical stress distribution before cutting the second coal. (c) Vertical stress distribution before backfilling. (d) Vertical stress distribution before the next coal cutting after backfilling.

the working face to the cut hole; the vertical stress distribution changes little in a cycle process

(3) Comprehensive analysis shows that the stress change of the working face is small in a backfilling cycle when the working face is pushed to $100 \mathrm{~m}$ away from the cut hole. Therefore, the pressure near the working face is less affected by the mining and backfilling cycle

\subsubsection{Stress Distribution of E1302 Backfilling Working Face} $100 \mathrm{~m}$ away from the Cut Hole. This section mainly studies the stress distribution of the working face 300 away from the cut hole and takes a full mining and backfilling cycle to study its stress distribution, so as to analyze the stress distribution law of the working face at this stage. At this time, the east, west, and north sides of the working face (in front of the working face) are solid coal, and behind the working face is the backfilling body, as shown in Figure 8 .

The following can be seen from Figure 8:

(1) It can be seen from the top view (a) that the stress concentration areas are mainly distributed in the west side of E1302 auxiliary transport roadway (coal pillar side), the east side of E1302 intake roadway, and the coal pillar between E1302 goaf and E1302 cut hole. Among them, the stress near the coal pillar between E1302 goaf and E1302 cut hole is the most concentrated, especially in the side near E1303 goaf, the maximum stress concentration coefficient can reach about 3.1, the second is the coal pillar on the west side of E1302 auxiliary transport roadway, which is affected by mining on both sides at the same time, and E1302 auxiliary transport roadway needs to be preserved to serve the lower layer mining, which makes the stress distribution in the roadway side pillar more concentrated, and the stress concentration coefficient is about 2.25. The influence of goaf on the coal pillar in the east of the E1302 intake roadway is small, so the stress concentration area is small. According to the stress distribution analysis in the top view, the stress change of the working face is very small in the backfilling and mining cycle. Within the range of $40 \mathrm{~m}$ in front of the working face, the stress concentration coefficient is between 1.25 and 2.0. The backfilling body in the west behind the working face is affected by the goaf, and the stress is greater than that of the backfilling body in the east

(2) According to the main view (b) in Figure 8, the coal mass in front of the middle part of the working face is still a stress concentration area, but the stress peak area changes and moves to the top of the working face roof

3.2.4. Stress Distribution of E1302 Working Face after the Backfilling and Mining. This section mainly analyzes the vertical stress distribution of the backfilling area and surrounding stress after the completion of backfilling and mining, as shown in Figure 9.

The following can be seen from Figure 9:

(1) It can be seen from the top view (a) that after the completion of mining and backfilling, the backfilling body is affected by the goaf, and the stress concentration factor of the two areas is relatively concentrated, especially the coal pillar in the south of E1302 and the north of E1302 goaf, and the maximum stress concentration coefficient can reach 3.14. In the paste backfilling area, the stress increases gradually from the stoppage line side of the working face to the E1302 cut hole. In the area affected by E1303 goaf, the stress in the west area is higher than that in the east area. In the area less affected by E1303 goaf, the stress on both sides of the paste backfilling area is basically symmetrical 

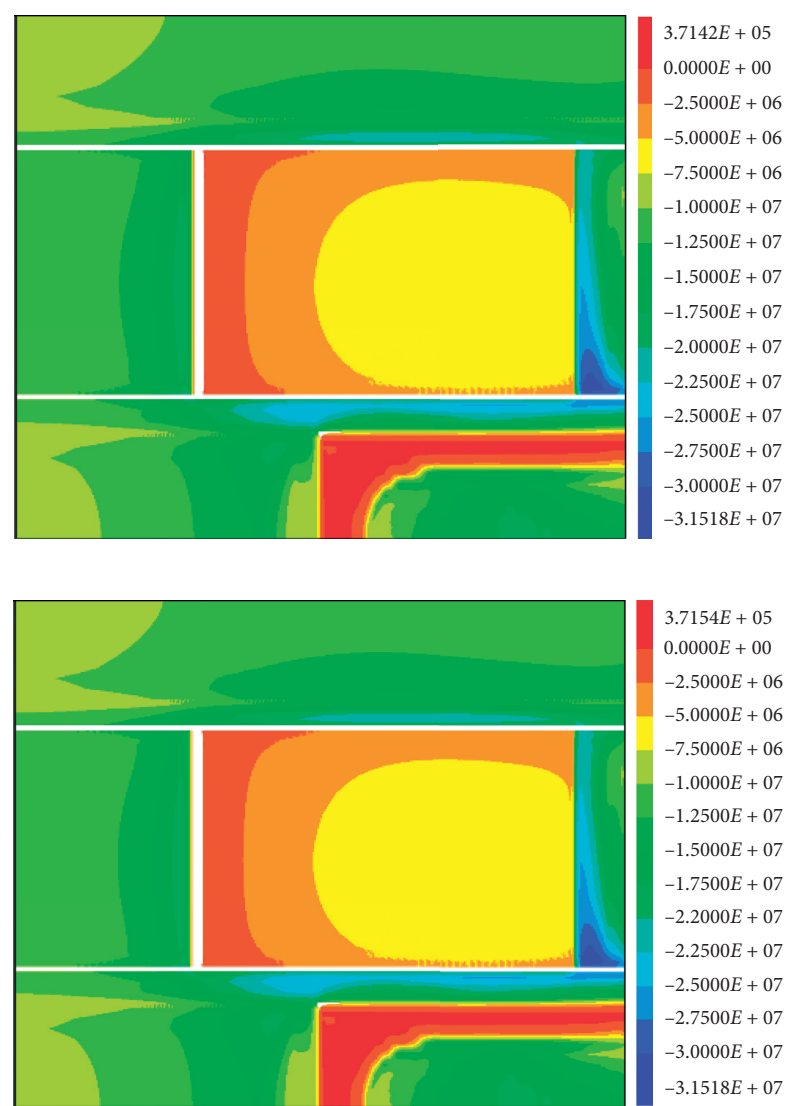

$3.7154 E+05$ $0.0000 E+00$

$-2.5000 E+06$

$-5.0000 E+06$

$-7.5000 E+06$ $-1.0000 E+07$

$-1.2500 E+07$

$-1.5000 E+07$

$-1.7500 E+07$

$-2.2000 E+07$

$-2.2500 E+07$

$-2.5000 E+07$

$-2.7500 E+07$

$-3.0000 E+07$

$-3.1518 E+07$

(b)

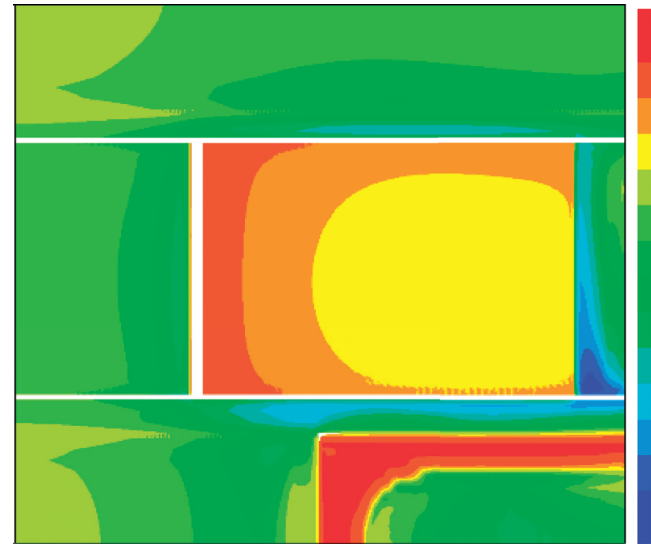

(a)



$3.3885 E+04$

$-1.0000 E+06$

$-3.0000 E+06$

$-5.0000 E+06$

$-7.0000 E+06$

$-9.0000 E+06$

$-1.1000 E+07$

$-1.3000 E+07$

$-1.5000 E+07$

$-1.7000 E+07$

$-1.9000 E+07$

$-1.9453 E+07$
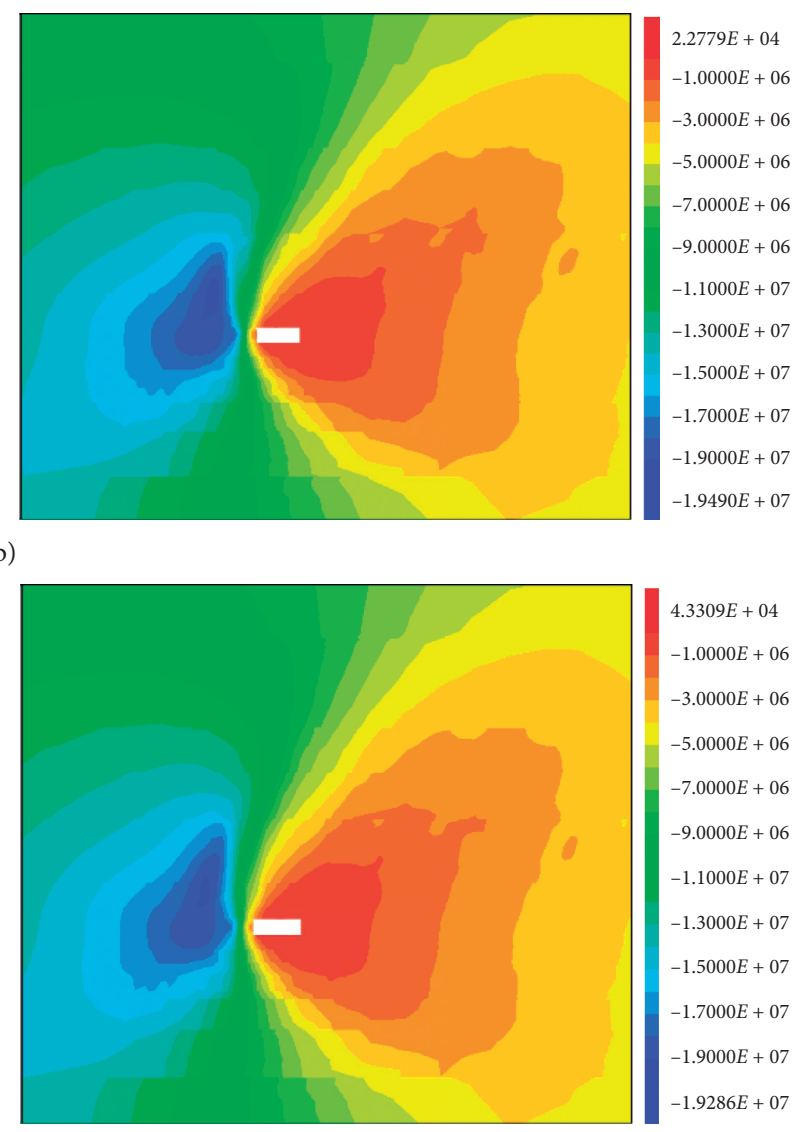

(c)

Figure 8: Continued. 

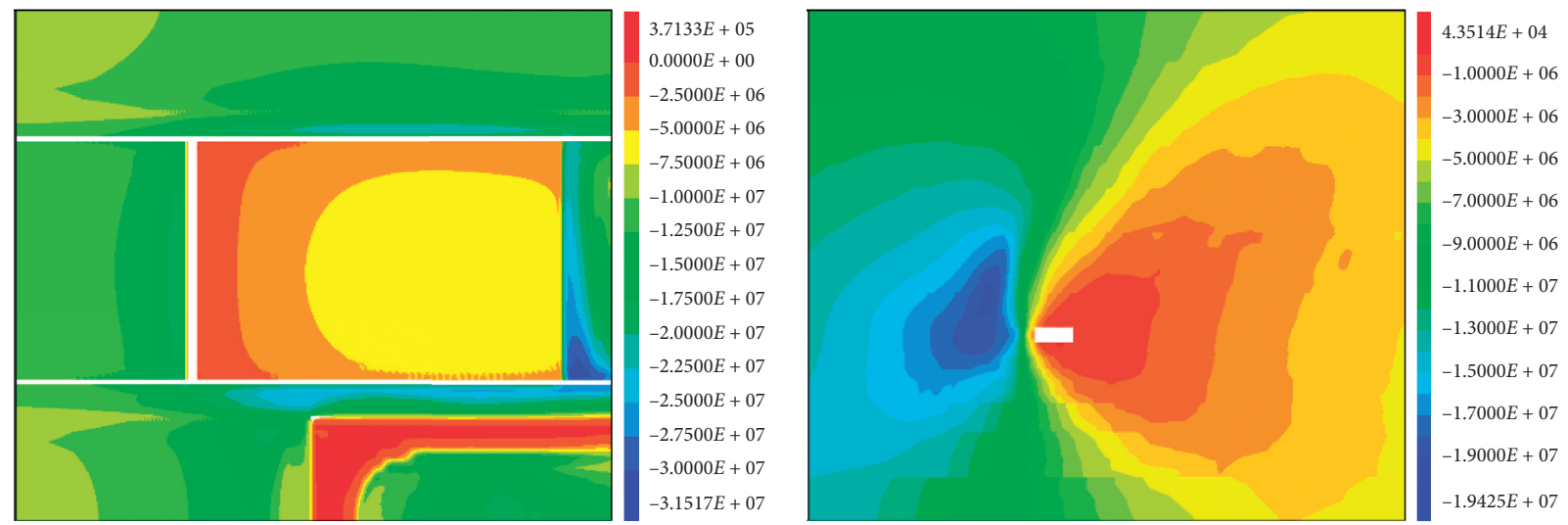

(d)

Figure 8: Nephogram of stress distribution $300 \mathrm{~m}$ away from the cut hole in E1302 working face under a backfilling mining cycle. (a) Vertical stress distribution before cutting the first coal. (b) Vertical stress distribution before cutting the second coal. (c) Vertical stress distribution before backfilling. (d) Vertical stress distribution before the next coal cutting after backfilling.

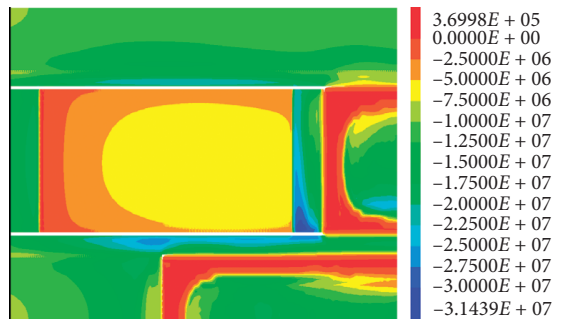

(a)



(b)

FIGURE 9: Nephogram of stress distribution of E1302 working face after filling and mining.

(2) It can be seen from the main view (b) in Figure 9 that the internal stress in the paste backfilling area is higher than that on both sides before and after the working face, and the stress is generally lower than the original rock stress. The stress concentration area is mainly concentrated in the local scope of the coal pillar in the south of the E1302 cut hole and the stoppage line in the north of the working face

\section{Conclusion and Prospect}

4.1. Conclusion. Aiming at the problems of low production capacity and high cost of paste backfilling in the coal mine, this paper takes the No. 3 Coal Seam in Lu'an area as the research object and studies the stress distribution law of high-efficiency paste backfilling working face in the thick coal seam above $6 \mathrm{~m}$, so as to solve the problem of solid waste backfilling mining in thick coal seam represented by Lu'an, so as to improve the recovery rate of mine resources and extend the service life of the mine.

(1) On the basis of the theoretical establishment of the instability criterion of roof rock beam failure with the change of backfilling body unit strength with time, a numerical calculation model considering the change process of backfilling body strength was established. The stress distribution law of E1302 working face before and during mining was analyzed, which played a guiding role in the actual production of the whole working face and roadway

(2) The recovery rate of resources is improved. It is preliminarily estimated that paste backfilling can make the recovery rate of No. 3 coal seam close to $80 \%$ and increase the recovery rate by nearly $40 \%$. 
More than 210 million tons of coal under buildings can be mined, effectively extending the service life of the mine and increasing employment opportunities

4.2. Research Prospect. On the basis of theory and practice, this paper makes a preliminary study on the stress distribution law of high-efficiency paste backfilling working face in thick coal seam above $6 \mathrm{~m}$ from the perspective of numerical simulation. Although some understanding and experience have been obtained, there are still many problems to be further studied, mainly reflected in the following aspects:

(1) It is necessary to refine the model, consider the influence of the stability of the coal side and backfilling side of longwall mining, improve the numerical simulation model, and provide a more solid numerical simulation basis for the wide application of backfilling mining

(2) The current numerical simulation research is only aimed at the conditions of Gaohe mine. The trend and direction of theoretical research and development of backfilling mining should be based on the specific situation of different production practices in the mining area, so as to reduce the difficulty of backfilling and mining technology, reduce the backfilling cost, improve the backfilling rate, control the surface subsidence, and promote the benign development of the mining area

\section{Data Availability}

The data used to support the findings of this study are included within the article. And all data are obtained through experiments and tests by our research team in Gaohe mine and laboratory. All the data are true and effective. The right to use data belongs to the authors before the article being published, but after it was published, the data can be referenced.

\section{Conflicts of Interest}

The authors declare no conflicts of interest.

\section{References}

[1] BP Global, BP Group Released BP World Energy Statistical Yearbook 2018: Process Industry, BP Global, London, UK, 2018.

[2] M. Zhang, Theoretical Study on Overburden Control of High Efficiency Paste Backfilling Working Face, China University of Mining and Technology, Xuzhou, China, 2019.

[3] X. Huang, "Leading energy industry reform with green development," People's Forum, vol. 31, pp. 26-27, 2017.

[4] National Bureau of Statistics, China Statistical Yearbook 2018, National Bureau of Statistics, Beijing, China, 2018.

[5] J. Peng and J. Dong, "Research of double layer filter-tube nonsand-mat vacuum preloading in ultra soft seabed silt hydraulic fill site," in Proceedings of the International Conference on Electric Information and Control Engineering (ICEICE), Wuhan, China, 2011.

[6] B. Ercikdi, "Utilization of industrial waste products as pozzolanic material in cemented paste backfill of high sulphide mill tailings," Journal of Hazardous Materials, vol. 168, pp. 848-856, 2009.

[7] L. Huynh, "Effect of polyphosphate and naphthalene sulfonate formaldehyde condensate on the theological properties of dewatered tailings and cemented paste backfill," Minerals Engineering, vol. 19, pp. 28-36, 2006.

[8] A. Philip, Engineering Design of Paste Backfill Systems, Queen's University Kingston, Ontario, Canada, 2003.

[9] C. G. Nicieza, M. I. Álvarez Fernández, A. Menéndez Díaz, and A. E. Álvarez Vigil, "The new three-dimensional subsidence influence function denoted by n-k-g," International Journal of Rock Mechanics and Mining Sciences, vol. 42, no. 3, pp. 372-387, 2005.

[10] M. Xie-Xing, Z. Ji-Xiong, and G. Guang-Li, "Study on wastefilling method and technology in fully-mechanized coal mining[J]," Journal of China Coal Society, vol. 35, no. 1, pp. 1-6, 2010

[11] P. Rajeev, P. R. Sumanasekera, and N. Sivakugan, "Lateral variation of the vertical stress in underground mine stopes filled with granular backfills," Geotechnical and Geological Engineering, vol. 34, no. 2, pp. 481-492, 2016.

[12] S. Widisinghe and N. Sivakugan, "Vertical stress isobars for trenches and mine stopes containing granular backfills," International Journal of Geomechanics, vol. 14, no. 2, pp. 313318, 2014

[13] M. Z. Emad, H. Mitri, and C. Kelly, "Effect of blast-induced vibrations on fill failure in vertical block mining with delayed backfill," Canadian Geotechnical Journal, vol. 51, no. 9, pp. 975-983, 2014.

[14] M. Qian, G. Xiexin Miao, J. Xu et al., "On scientific mining," Journal of Mining and Safety Engineering, vol. 25, no. 1, pp. 1-10, 2008.

[15] M. Qian, "Scientific mining of coal and related issues," China Coal, vol. 34, no. 8, pp. 5-10, 2008.

[16] M. Qian and J. Xu, "Concept and technical framework of scientific mining," Journal of China University of Mining and Technology, vol. 13, no. 3, pp. 1-7, 2011.

[17] M. Qian, "Scientific mining of coal," Journal of China Coal Society, vol. 35, no. 4, pp. 529-534, 2010.

[18] M. Qian, J. Xu, and J. Wang, Further Discussion on Scientific Mining of Coal, Journal of China Coal Society, Beijing, China, 2018.

[19] J. Xu, "Strata control and coal scientific mining: academician Qian Minggao's academic thoughts and scientific research achievements," Journal of Mining and Safety Engineering, vol. 1, 2019.

[20] T. Liu, Backfilling Mining Technology and its Application, Metallurgical Industry Press, Beijing, China, 2001.

[21] A. Zhou, Cemented Backfilling of Mine Waste, Metallurgical Industry Press, Beijing, China, 2007.

[22] W. Peng, "FLAC 3D practical course," 2008.

[23] Y. Chen and D. Xu, FLAC3D Foundation and Engineering Examples, China Water Conservancy and Hydropower Press, Beijing, China, 2013. 